ISSN: 0213-2060

DOI: https://doi.org/10.14201/shhme201937293112

\title{
DE OFICIAL ADMINISTRATIVO A AGENTE FINANCEIRO: EVOLUÇÃO DO CARGO DE BEDEL NO STUDIUM GENERALE PORTUGUÊS (1309-1537) ${ }^{1}$
}

\author{
From Administrative Officer to Financial Agent: Evolution of the Position of Beadle \\ in the Portuguese Studium Generale (1309-1537) \\ Ana Pereira FERREIRA \\ CIDEHUS-UÉvora. Largo do Marquês de Marialva 8. 7000-654 ÉVORA. Centro de História da Universidade \\ de Lisboa. Faculdade de Letras. Universidade de Lisboa. Alameda da Universidade. 1600-214 LISBOA. PIUD- \\ Hist. C e: anapsferreira@gmail.com \\ Rui M. ROCHA \\ Centro de História da Universidade de Lisboa. Faculdade de Letras. Universidade de Lisboa. Alameda da Univer- \\ sidade.1600-214 LISBOA. PIUDHist. C. e: ruimrocha92@gmail.com
}

Recibido: 2019-01-28

Revisado: 2019-04-08

Aceptado: 2019-11-08

RESUMO: A universidade medieval, enquanto instituição cultural por excelência e veículo essencial da produção e desenvolvimento intelectual da Europa de entáo, era constituída por corpos académicos, entre os quais o oficialato do Estudo, responsável pela administração e burocracia universitária. Nesse sentido, propomos tratar de um dos mais importantes oficiais da universidade medieval: o bedel. Neste artigo, com base em documentação régia e estatutária, propomos uma análise das características (formação académica, métodos de recrutamento, duração de carreiras, mecanismos de remuneraçáo, serviço à coroa e igreja) e da evolução das funçóes deste cargo na universidade portuguesa, entre 1309 (correspondente ao primeiro momento em que ofício aparece documentado) e 1537 (ano da transferência definitiva para a cidade de Coimbra), enfatizando as transformaçóes que atribuiriam ao referido cargo uma dimensão económica e financeira, bem como um elevado grau de responsabilidade na preservação da esfera material da universidade.

Palavras-chave: Bedel; Universidade; Idade Média; Portugal.

1 Este trabalho é financiado por Fundos FEDER através do Programa Operacional Factores de Competitividade - COMPETE e por Fundos Nacionais através da FCT - Fundação para a Ciência e a Tecnologia no âmbito do projeto «OECONOMIA STUDII». Financiamento, gestäo e recursos da universidade em Portugal: uma análise comparativa (séculos XIII-XVI) $=$ «OECONOMIA STUDII». Funding, management and resources of the Portuguese university: a comparative analysis (13 th $-16^{\text {th }}$ Centuries) (PTDC/EPHHIS/3154/2014). 
ABSTRACT: The medieval university, as a cultural institution par excellence and an essential vehicle for the intellectual production and development of Europe at that time, consisted of several academic bodies, among them the officials, responsible for the administration and university bureaucracy. For this reason, we propose to study one of the most important officers of the medieval university: the beadle. In this article, we propose an analysis of the characteristics (academic formation, recruitment methods, careers lengths, remuneration mechanisms, service to the crown and church) and the evolution of the functions of this position in the Portuguese university, between 1309 (corresponding to the first moment in which the beadle appears documented) and 1537 (year of the definitive relocation to Coimbra), emphasizing the transformations that would give the mentioned post an economic and financial dimension, as well as a high degree of responsibility in the preservation of the material sphere of the university.

Keywords: Beadle; University; Middle Ages; Portugal.

SUMÁRIO: 0 Introdução. $1 \mathrm{O}$ bedel na universidade: da Europa a Portugal. 1.1 Caracterização e evolução do ofício. $2 \mathrm{Da}$ administração às competências financeiras. 2.1 Evoluçáo funcional do ofício. 2.2 Mecanismos de remuneração do ofício. 3 Carreiras e percursos do bedelado português. 4 Consideraçôes finais. 5 Referências bibliográficas.

\section{INTROdUÇÃo}

As primeiras notícias que nos chegam sobre o desejo de criar uma universidade no reino de Portugal datam do final do século XIII ${ }^{2}$. O monarca de então, D. Dinis (12791325), procurava apoios junto do clero português para a constituição de um Estudo Geral. Contudo, apenas dois anos mais tarde a documentação nos dá conta da constituição da universidade através da bula do Papa Nicolau IV intitulada De statu Regni Portugalie ${ }^{3}$.

O Santo Padre aprovava assim a súplica enviada pelos prelados portugueses, concedendo um conjunto de privilégios aos escolares e autorizando a formação e concessão de graus em Artes, Cânones, Leis e Medicina, sendo que deveria ser o bispo a atribuir esses mesmos graus aos estudantes.

A Universidade era fundada em finais da centúria de Duzentos e Lisboa a cidade escolhida para se estabelecer. Ainda que não possamos falar do conceito de capital para esta cronologia, a verdade é que no reinado dionisino e posteriormente no reinado de D. Afonso IV (1325-1357), Lisboa ganhava cada vez mais importância pelas trocas comerciais, pela proximidade ao mar e pela presença cada vez mais frequente da corte régia. Ainda assim, em 1308, por razóes nem sempre explícitas, o Estudo Geral Português seria transferido para a cidade de Coimbra, conforme nos demonstra a bula de Clemente $V^{4}$.

2 Existem algumas dúvidas quanto à data exacta de fundação da Universidade medieval portuguesa. Temos a resposta a um pedido de vários prelados ao Papa com a data de 1290, ainda que não se saiba exactamente se não funcionaria já antes desta cronologia.

3 Rodrigues, Manuel Augusto e Veloso, Maria Teresa Nobre (eds.). Livro Verde da Universidade de Coimbra. Coimbra: Arquivo da Universidade, 1992, p. 3.

4 Rodrigues e Veloso (eds.), Livro Verde da Universidade de Coimbra, p. 11. 
DE OFICIAL ADMINISTRATIVO A AGENTE FINANCEIRO: EVOLUÇÃO DO CARGO DE BEDEL NO STUDIUM GENERALE PORTUGUÊS (1309-1537)

ANA PEREIRA FERREIRA E RUI M. ROCHA

A itinerância do Estudo entre Lisboa e Coimbra seria uma especificidade própria e única da Universidade medieval portuguesa, que várias vezes transitaria entre as duas cidades. Facto é que em 1338, no reinado de Afonso IV, o Estudo viria novamente a ser deslocado para Lisboa, sob o argumento do rei não conseguir ter pousada em Coimbra e devido às queixas frequentes dos habitantes da cidade pelo rebuliço causado pelos escolares ${ }^{6}$. Pouco tempo ficaria em Lisboa, uma vez que em 1354 o mesmo monarca viria a conduzir a Universidade a mais uma mudança para Coimbra, sendo que desta feita seria a Peste Negra a ditar a mudança ${ }^{7}$. Seria D. Fernando (1366-1383) quem viria a restabelecer de forma mais ou menos definitiva a presença do Estudo em Lisboa. Justificava a sua decisão com o facto de que apenas para esta cidade seria possível a vinda de mestres e escolares de outros reinos e assim engrandecer a importância da Universidade medieval ${ }^{8}$. Aqui permaneceria até 1537, quando seria transferida definitivamente para Coimbra, por D. João III (1521-1557).

Para o bom funcionamento da Universidade, era necessário um corpo docente e discente que desempenhasse um conjunto de funçôes. Contudo, pela própria exigência da orgânica de um Estudo Geral seriam necessários, além dos mestres e escolares, os oficiais que garantissem o bom funcionamento da instituição, que desempenhavam um papel crucial para a manutenção da mesma.

De entre estes oficiais, como veremos adiante, estaria a figura do bedel. É de resto este cargo que pretendemos abordar nesta nossa reflexão, considerando as suas características, entre as quais a formação académica, métodos de recrutamento, duração de carreiras, bem como, sempre que possível, abordar as semelhanças e diferenças face a algumas Universidades medievais da Christianitas, como o caso de Paris e Salamanca.

Em suma, com base na regulamentação do bedelado, os objetivos são ilustrar a importância do ofício de bedel para a orgânica estrutural da Universidade medieval portuguesa e em última análise, compreender a evolução funcional do cargo e consequente aumento de competências, acompanhado de alteraçóes paradigmáticas nas formas de remuneração e mecanismos financeiros do ofício, bem como as crescentes responsabilidades na esfera material do Estudo.

Quanto ao Status Quoestiones para o cargo de bedel, as informaçóes são escassas, fruto da também parca existência de fontes para o caso português. No contexto inter-

5 Martins, Armando. «Lisboa, a cidade e o Estudo: a Universidade de Lisboa no primeiro século da sua existência». In Fernandes, Hermenegildo (coord.). Universidade Medieval em Lisboa séculos XIII-XVI. Lisboa: Tinta da China, 2013, p. 49.

6 Este é, de resto, um assunto que tem sido já abordado pela historiografia. Veja-se o nosso artigo «A cidade e a Universidade: indícios de exclusão social dos escolares nos alvores do Estudo Geral Português». In Solórzano Telechea, Jesús Ángel (coord.). Exclusión y orden social en la ciudad medieval europea. Logroño: Instituto de Estudios Riojanos, 2018, pp. 91-120; MarTins, «Lisboa, a cidade e o Estudo: a Universidade de Lisboa no primeiro século da sua existência», pp. 41-88. Verifique-se ainda Coeluo, Maria Helena da Cruz. «Coimbra et l'université: complémentarités et oppositions». In Gilli, Patrick; Verger, Jacques e Le BLÉveC, Daniel. Les universités et la ville au Moyen Âge. Cohabitation et tension. Turnhout: Brill, 2007, pp. 309-326.

7 Martins, «Lisboa, a cidade e o Estudo: a Universidade de Lisboa no primeiro século da sua existência", p. 60.

8 Rodrigues e Veloso (eds.), Livro Verde da Universidade de Coimbra. pp. 67-71. 
nacional, temos a obra de Ruegg e Symoens ${ }^{9}$, que nos traça um panorama geral sobre as Universidades na Europa e alguns esclarecimentos sobre o cargo de bedel. Para a Universidade de Salamanca, temos o artigo de García y García que nos elucida sobre a génese daquela universidade, abordando também algumas das especificaçôes do cargo de bedel para a instituição ${ }^{10}$.

Por outro lado, em termos nacionais apenas podemos contar com um conjunto muito breve de contributos: Artur Moreira de Sá aborda sumariamente o bedel na sua obra sobre o protetorado do Infante D. Henrique ${ }^{11}$ sem no entanto constituir qualquer novidade; Maria Helena da Cruz Coelho ${ }^{12}$, num artigo conciso mas fundamental a propósito das finanças da Universidade, refere brevemente as formas de sustentação económica do oficialato do Estudo Geral português, entre os quais se insere o bedel; de contar ainda com as referências dadas na obra coordenada por Hermenegildo Fernandes, desta vez a propósito da história da Universidade de Lisboa ${ }^{13}$, onde são traçadas algumas carreiras e dadas informaçôes adicionais sobre o ofício. De referir ainda o recentemente publicado artigo de Cruz Coelho, Hermínia Vilar e Hermenegildo Fernandes na Studia Historica $^{14}$, em que abordam aspectos da fundaçáo da universidade portuguesa e os meios financeiros que foram usados para a sua subsistência.

Naturalmente que a bibliografia sobre Universidades medievais não se resume a estes títulos, mas efectivamente, sobre o bedel, ainda muito existe a explorar e a compreender, havendo muito pouca informação já publicada.

No que a fontes diz respeito, além da documentação avulsa por vezes encontrada nos fundos dos arquivos nacionais, temos essencialmente a informação compilada no Livro Verde da Universidade de Coimbra ${ }^{15}$ e no Chartularium Universitatis Portucalensis ${ }^{16}$. Além destas, esperamos que o projecto de investigação Oeconomia Studii, cujo propósito é analisar as fontes publicadas referidas anteriormente, mas também documentação inédita dos arquivos portugueses (nomeadamente no Arquivo Nacional/Torre do Tombo, no Arquivo da Universidade de Coimbra e no Arquivo Municipal de Lisboa/Histórico),

9 RuegG, Walter e RidDer-Symoens, Hilde de. Uma História da Universidade na Europa I. As Universidades na Idade Média. Lisboa: INCM-Imprensa Nacional Casa da Moeda, 1996.

10 García y García, Antonio. «Génesis de la Universidad, siglos XiII-XIV». In Rodríguez-San Pedro Bezares, Luis E. (coord.). Historia de la Universidad de Salamanca. I, Trayectoria y vinculaciones. Salamanca: Ediciones Universidad de Salamanca, 2002, pp. 21-38.

11 Moreira De SÁ, Artur. O Infante D. Henrique e a Universidade. Lisboa: Comissão Executiva das Comemoraçôes do Quinto Centenário da Morte do Infante D. Henrique, 1960, p. 127.

12 Coelho, Maria Helena da Cruz. «As Finanças». In História da Universidade em Portugal. Lisboa: Fundaçáo Calouste Gulbenkian, 1997, vol. I, tomo I, pp. 39-67.

13 Fernandes, Hermenegildo (coord.). História da Universidade Medieval em Lisboa. Séculos XIII-XVI. Lisboa: Tinta da China, 2013.

14 Coelho, Maria Helena da Cruz; Fernandes, Hermenegildo e Vilar, Hermínia. «O Studium medieval português: singularidades de um caso periférico». Studia Historica. Historia Medieval, 2018, vol. 36, n. ${ }^{\circ} 2$, pp. $83-115$.

15 Rodrigues e Veloso (eds.), Livro Verde da Universidade de Coimbra.

16 Moreira de SÁ, Artur [et al.] (eds.). Chartularium Universitatis Portugalensis (1288-1537). 16 vols. Lisboa: Instituto de Alta Cultura-Instituto Nacional de Investigação Científica-Junta Nacional de Investigaçâo Científica e Tecnológica-Fundação para a Ciência e a Tecnologia, 1966-2004. 
DE OFICIAL ADMINISTRATIVO A AGENTE FINANCEIRO: EVOLUÇÃO DO CARGO DE BEDEL

NO STUDIUM GENERALE PORTUGUÊS (1309-1537)

ANA PEREIRA FERREIRA E RUI M. ROCHA

possa vir a trazer novos informes sobre o financiamento do Estudo Geral e inclusive sobre os seus oficiais, designadamente, o bedel.

\section{O bedel na Universidade: da Europa a Portugal}

\subsection{Caracterização e evolução do ofício}

A Universidade medieval, enquanto instituição cultural por excelência e veículo essencial da produção e desenvolvimento intelectual da Europa de então, era constituída por corpora académicos e independentemente das sobreposições entre categorias, é possível, de entre estes corpos, identificar em pleno três grupos, bem delineados e distintos entre si: os escolares, os mestres e o oficialato do Estudo.

Pela informação que nos é transmitida pela bibliografia sobre a Universidade medieval, em concreto a obra Uma História da Universidade na Europa I. As Universidades na Idade Média, de Walter Ruegg e Hilde de Ridder-Symoens ${ }^{17}$, ficamos a saber que ao bedel nas Universidades da Christianitas cabiam funçôes de vários tipos: além de serem uma espécie de braço direito dos procuradores da Universidade, precediam aos reitores, reuniam votos da congregação, liam listas de materiais de leitura obrigatória, guardavam as listas de livros à venda, anunciavam disputas, guardavam listas de graduaçôes, liam as proclamaçóes de estatutos, cobravam taxas e multas, registavam os condenados à prisão, anunciavam as reunióes do tribunal académico, preservavam os materiais e as instalaçóes das Universidades, entre outras funçôes. Tinham vestuário, insígnias e bastão próprios (massa). No caso português, de acordo com os estatutos universitários de 1503, pelo menos no início do século XVI, o bedel também se distinguia pelo uso do bastão próprio $(\text { massa })^{18}$.

O bedelado era um cargo que em algumas Universidades era por eleição, mas noutras, como as francesas, podia ser um cargo venal. Jacques Verger chama a atenção para a universidade de Avinhão, na qual o bedel aparece, em 1463, a pagar 200 florins pelo cargo $^{19}$, o que transmite a ideia de ser um cargo desejável. Na verdade, o bedel era considerado um cidadão da cidade universitária, quase tão antigo quanto a mesma, augurando o respeito da comunidade e usufruindo de um conjunto de privilégios e isençóes.

Para o caso da Universidade de Salamanca, diz-nos García y García que alguns actos do bedel aparecem muitas vezes em registos do século xv, tendo então muito mais importância que aquela que lhe é dada na contemporaneidade. O bedel além de dar fé pública ao que lavrava, os seus documentos teriam cariz oficial. Abaixo dele estaria um corpo de oficiais, escolhido de um núcleo da sua confiança para assegurar que todas as funçóes

\footnotetext{
17 Ruegg e Ridder-Symoens, Uma História da Universidade na Europa I. As Universidades na Idade Média.

18 E ho bedel diante com sua maça. Rodrigues, Manuel Augusto (ed.). Os primeiros estatutos da Universidade de Coimbra. Coimbra: Arquivo da Universidade de Coimbra, 1991, p. 36.

19 Verger, Jacques. «Déspenses universitaires à Avignon au XV siècle (1455-1456)». In Institut de Recherches et d'Etudes du Bas Moyen Âge Avignonnais [et al.]. Avignon au Moyen Âge. Textes et documents. Avignon: Aubanel, 1988, p. 212.
} 
eram desempenhadas de acordo com o previsto. Além disso cabia-lhe, entre outras coisas, confirmar os votos e servir de testemunha, assemelhando-se em muitos aspectos a um secretário das universidades de hoje $\mathrm{e}^{20}$. Teria também funçôes de validação do ensino privado, anunciando publicamente as horas de leitura ${ }^{21}$. À semelhança do caso português, estaria presente e anunciava sempre que um novo grau era atribuído a um escolar ${ }^{22}$.

Em alguns casos, existia um Bedellus minor ou subbedellus, que coadjuvava as funçôes do bedel principal. Naturalmente, tal só se justificava em Universidades de maior dimensão, o que não era o caso do Estudo Geral Português.

De qualquer modo, as informaçóes que nos chegam escritas pelos bedéis, tal como pelos chanceleres ou mensageiros das Universidades são extremamente importantes, para termos uma compreensão profunda sobre o funcionamento das mesmas.

O bedel da Universidade portuguesa é um oficial conhecido na documentação pelo menos desde 1309, inicialmente com funçóes eminentemente burocráticas, as quais vão evoluindo diacronicamente, tornando-o imprescindível ao funcionamento da instituição.

Em Portugal, como já referimos, as informações não são muitas, mas podemos verificar algumas semelhanças e contrastes com os casos europeus: no Estudo português, como já notado, não existia um subbedellus, provavelmente porque também o Estudo Geral não teria dimensão que o justificasse. Contudo, existe a possibilidade de o bedel se ausentar e ser substituído provisoriamente por outro indivíduo, desde que conte com o beneplácito régio. Exemplo disso é o que acontece em 1456, quando D. Afonso V autoriza a que o bedel Pero da Cruz se possa fazer substituir por alguém competente ${ }^{23}$. Por outro lado, se na maioria das Universidades o bedel era um apoio fundamental ao procurador, no caso português, este oficial aparecia frequentemente enquanto procurador ele mesmo, como iremos atentar adiante.

Pontualmente vamos tendo referências a mais algumas funçóes do bedel no reino português: deveria ser também o escrivão das rendas e estar em permanente contacto com o sacador para pagamentos.

Aquando as doações de casas para o funcionamento do Estudo por parte do Infante D. Henrique (1431) é também estipulado que o bedel deve morar numa dessas casas, de forma a poder guardar as mesmas ${ }^{24}$.

O oficial deveria ser ainda o responsável por matricular os estudantes em cada ano, ouvindo além disso o juramento dos escolares. Estaria igualmente a seu cargo a verificação da eleição do reitor e o controlo da assiduidade dos lentes, registando as faltas destes. Era o bedel responsável pela fiscalização das armas na posse de escolares, que não poderiam entrar armados nas escolas, e pelo controlo da roupa dos estudantes, que não estivesse conforme as prescriçóes estatutárias.

20 García y García, Antonio. «Consolidaciones del siglo XV». In Rodríguez-San Pedro Bezares, Luis E. (coord.). Historia de la Universidad de Salamanca. I, Trayectoria y vinculaciones. Salamanca: Ediciones Universidad de Salamanca, 2002, pp. 45 e 46.

21 García y García, "Consolidaciones del siglo XV», p. 53.

22 García y García, "Consolidaciones del siglo XV», p. 55.

23 Rodrigues e Veloso (ed.), Livro Verde da Universidade de Coimbra, p. 198.

24 Rodrigues e Veloso (ed.), Livro Verde da Universidade de Coimbra, pp. 181-187. 
DE OFICIAL ADMINISTRATIVO A AGENTE FINANCEIRO: EVOLUÇÃO DO CARGO DE BEDEL NO STUDIUM GENERALE PORTUGUÊS (1309-1537)

ANA PEREIRA FERREIRA E RUI M. ROCHA

Ainda dentro das atribuições do cargo de bedel, estava a intendência das audiências feitas pelo conservador, bem como a função de cumprir e publicar os autos que fossem feitos pelo reitor, conselheiros, deputados e lentes.

Dentro das ocupaçóes do bedel constava a de ser o escriváo do Estudo, controlando também as receitas e despesas da Universidade, as rendas e os pagamentos.

Sempre que um escolar se apresentasse a exame para obtenção de grau, cabia ao bedel receber o juramento e publicar os resultados desse exame, além de recolher os votos de aprovado e reprovado nas provas.

Por fim, de entre as obrigaçôes do ofício de bedel, está a divulgação de cátedra vacante e o controlo e registo dos nomes dos estudantes e dos seus votos para a nova eleiçáo para a cátedra vaga.

Dentro da orgânica do estudo, como é possível verificar no organograma (ver fig. 1), o bedel é precedido e responde perante o reitor, e respetivo conselho e corpo de deputados.

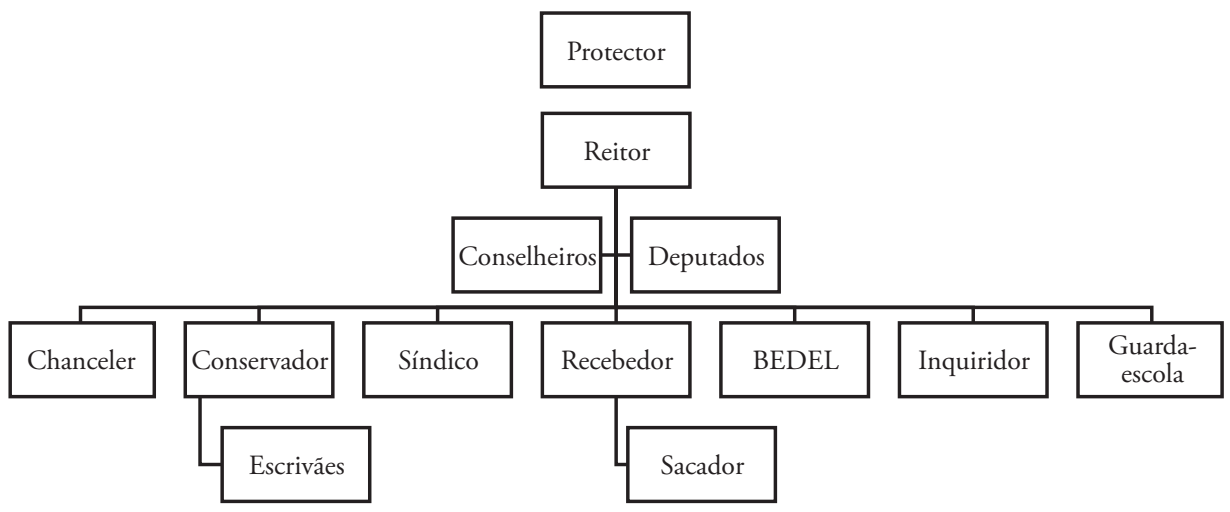

FIG. 1. Organograma do Estudo Geral Português.

A um nível semelhante de importância nas funções atribuídas, temos o chanceler, o conservador e o inquiridor da Universidade, além de outros oficiais.

Efectivamente, a primeira vez que deste oficial temos notícia é na já referida Magna Carta de D. Dinis, quando menciona que o mesmo devia ser eleito pelos escolares: havemos por bem conceder aos mesmos escolares que possam nomear os seus reitores e conselheiros, $o$ bedel e outros oficiais, que faräo prosperar o mais possivel o estado da Universidade ${ }^{25}$.

Uma particularidade do bedel no Estudo nacional é ainda o de, a partir de 1390, ser dado por D. João I (1385-1433) como tabelião da Universidade ${ }^{26}$. Tal benesse régia derivou do pedido que o Estudo dirigiu ao monarca, onde indicava que haveriam poucos tabeliães e que isso por vezes os prejudicava, aquando a necessidade de lavrar um documento com fé pública e autoridade. Além desse reparo, o reitor refere ainda que há assuntos que são da Universidade e que deveriam ser mantidos em sigilo.

25 Rodrigues e Veloso (ed.), Livro Verde da Universidade de Coimbra, p. 23.

26 Rodrigues e Veloso (ed.), Livro Verde da Universidade de Coimbra, pp. 117-118. 
Estas justificaçóes bastaram para o rei emitir o alvará onde dá como tabelião do Estudo o bedel, o qual deveria ainda assim, e como todos os tabeliáes régios, ser submetido a um exame na Chancelaria Régia e depositar lá o seu sinal.

A justificação apresentada pela Universidade sobre a falta de tabeliáes é algo que não nos parece verosímil: no reinado joanino podemos contar com cerca de 100 tabeliães, sendo que apenas no ano do documento em causa, temos não menos de 40 homens a lavrar documentos com fé pública na cidade de Lisboa ${ }^{27}$.

O pedido do Estudo Geral pode, no entanto, significar uma forma do próprio exercer alguma pressão e tentativa de supremacia sobre outras instituiçôes, nomeadamente o concelho, ao terem este favorecimento régio, tornando-se de alguma forma independentes do tabelionado citadino. Ainda assim, de frisar que o Estudo continua a solicitar documentos, nomeadamente traslados, a tabeliães de Lisboa.

Contudo, como veremos adiante, as funções do bedel foram aumentando e contendo um cariz cada vez mais de controlo e responsabilidade financeira, mantendo ainda assim as suas funções administrativas.

\section{DA ADMINISTRAÇÃO ÀS COMPETÊNCIAS FINANCEIRAS}

\subsection{Evolução funcional do ofício}

Ora, após ter sido feita uma breve, mas necessária, introdução sobre as características e orgânica do ofício de bedel, na qual fica bem expressa a sua importância para o funcionamento regular do Estudo Geral, tanto no caso singular de Portugal, como nas restantes Universidades onde marcou presença, importa agora traçar a evolução funcional do ofício, ou seja, descrever a evolução e acumulação de funçôes do bedelado português, determinado sobretudo por textos de natureza estatutária, mas também por outro tipo de documentação, como iremos observar.

Apesar do primeiro indivíduo documentado como bedel surgir apenas em 1326 (sendo este João Domingues) $^{28}$, está atestado documentalmente a prescrição régia da obrigatoriedade de existência de um bedel, nomeado pelos escolares, no Estudo Geral português, pelo menos desde o momento da sua transferência inaugural para Coimbra no final da primeira década de trezentos, sem, no entanto, nos dar quaisquer informes sobre as suas funçôes e responsabilidades. Falamos da Magna Charta Previligiorum (considerados os primeiros estatutos da Universidade) emitida pelo monarca D. Dinis em 1309, na qual a Coroa regulamenta a instalação do Estudo Geral na cidade de Coimbra. No documento, no que ao nosso tema diz respeito, D. Dinis limita-se a conceder aos escolares o direito à nomeação de vários oficiais, entre os quais o bedel. No documento afirma havemos por bem conceder aos mesmos escolares que possam nomear os seus reitores $e$

27 Informação fruto da investigação em curso de Ana Pereira Ferreira para a sua tese de doutoramento intitulada $A$ Cidade de Lisboa e a Universidade: o tabelionado régio e o poder da escrita, 1377-1438, ainda em execução no âmbito do Programa Interuniversitário de Doutoramento em História.

28 Moreira de Sá [et al.] (eds.), Chartularium Universitatis Portugalensis. 1288-1537, vol. 1, pp. 94-95 (doc. n.o 70). 
DE OFICIAL ADMINISTRATIVO A AGENTE FINANCEIRO: EVOLUÇÃO DO CARGO DE BEDEL NO STUDIUM GENERALE PORTUGUÊS (1309-1537)

ANA PEREIRA FERREIRA E RUI M. ROCHA

conselheiros, o bedel e outros oficiais, que farão prosperar o mais possivel o estado da universidade $^{29}$. O bedel, tinha então como desígnio fundamental auxiliar no sucesso da instituição, sem, no entanto, estar vinculado documentalmente a qualquer especificidade de funções.

Seria necessário esperar até 1377 , para ter a primeira notícia relativa às funçóes do bedel, ainda que de forma indireta. No documento de transferência da Universidade, desta vez da cidade de Coimbra para Lisboa, no qual confirma diversos privilégios e regulamenta a instalação na capital, o monarca D. Fernando (1367-1383) determinou que só circulassem e valessem os documentos que fossem redigidos pelo bedel. Diz-nos o documento Outrossi, nos pedio que fosse nossa merçee que se algua carta saisse do dicto studo que ao studo pertencesse que no saise se no per conselho dos reitores e lentes e conselheiros e scripta per o bedel que for dado ao dito studo e em outra guisa que nom vallese ${ }^{30}$. A isto, Armando Martins chama de «a primeira forma de chancelaria própria que o Estudo acabava de alcançar» ${ }^{31}$. Atribui-se assim ao bedel o importante papel, ou mesmo o protagonismo, na redação e validação dos documentos da Universidade portuguesa, menos de um século após a sua fundação. É, no entanto, importante ressalvar que é possível que esta função já se verificasse anteriormente, e que a sua codificação decorresse de uma prática que se considerava comum. Também na vizinha Espanha, de acordo com os casos estudados de Salamanca e Valladolid, o bedel dava fé pública nos documentos que lavrava, tornando -os probatórios em caso de contenda ${ }^{32}$.

Por outro lado, o ano de 1390 é um momento paradigmático e de viragem na história deste ofício, quando, após pedido da Universidade, a Coroa concede ao Estudo o privilégio de ter, na pessoa do bedel, tabelião privativo para autenticar a documentação relativa aos assuntos da instituição, com o intuito de salvaguardar o sigilo dos negócios da Universidade. No documento, datado de 4 de Novembro de 1390, está expresso que per mingoa de taballiam seu que nom teem e por esto dam os segredos da dita universsidade e studo. Pidirom nos por merçee que lhes dessemos por taballiam o bedel que for do dito studo e universsidade o qual mandamos que dee fe em todallas scripturas e contractos ${ }^{33}$, pedido este prontamente acedido pelo monarca D. João I, como já referimos anteriormente. A Universidade portuguesa conquistava assim uma autonomia burocrática centrada no bedel, que podemos considerar, agora sim codificado e sem margem para dúvidas, uma forma primitiva de chancelaria própria para a produção dos seus diplomas. Por justaposição, nesse mesmo ano, o cargo adquiria uma dimensão de relevo no que respeita aos recebimentos da instituição, no momento em que o monarca determina que não fossem despendidas rendas sem o conhecimento do bedel, por este ser simultaneamente escrivão

29 Rodrigues (ed.), Os primeiros estatutos da Universidade de Coimbra, p. 7.

30 Rodrigues e Veloso (ed.), Livro Verde da Universidade de Coimbra, pp. 70-71.

31 Martins, «Lisboa, a cidade e o Estudo: a Universidade de Lisboa no primeiro século da sua existência», p. 80 .

32 García y García, «Génesis de la Universidad, siglos XiII-XIV»; e Sánchez Movellán, Elena. «La época medieval». In Palomares IbáÑez, Jesús María (coord.). Historia de la universidad de Valladolid, I. Valladolid: Universidad de Valladolid, 1989.

33 Moreira de SÁ [et al.] (eds.), Chartularium Universitatis Portugalensis. 1288-1537, vol. 2, p. 197 (doc. n. 450 ). 
das ditas, desta vez com intuito de salvaguardar a transparência dos negócios do Estudo. Diz o documento E que porem nos pediam por merçee que lhes dessemos por scripvam das ditas Rendas afonso giraldez bedel da dita universsidade ou qualquer outro que bedel for pello tenpo pera seere, per elle certos do que as Rendas Rendem e podem montar e como se despendem E pera se fazer como deve. E Nos veendo o que nos pediam e querendo lhes fazer graça e merçee ao dito studo damos lhe por scripvam o dicto afomso giraldez bedel ou qualquer outro que beder for por scripvam das dictas Rendas ${ }^{34}$.

Desta forma, o oficio de bedel (que congregava por inerência o cargo de escrivão das rendas) transitava de um carácter meramente administrativo, como aliás era comum nas instituiçóes homólogas noutros reinos europeus, para uma dimensão vincadamente económica, com responsabilidades acrescidas de manutenção e preservação da dimensão material e financeira do Estudo Geral Português.

No dia 7 de dezembro de 1415, a Universidade de Lisboa emite um acordo que regulamenta alguns aspetos do cargo, que ficaria conhecido como o Regimento do bedel. Apesar da sua importância, o documento não regulamenta verdadeiramente o ofício. $\mathrm{O}$ que acontece é o seguinte: na sequência de um desacordo entre os escolares e o então bedel João de Braga acerca dos montantes a pagar pelos primeiros ao segundo, no qual os escolares se queixavam naturalmente de pagar demasiado, os reitores reuniram conselho para decidir os valores das coletas a cobrar anualmente ${ }^{35}$. Neste caso o pagamento atenderia critérios de riqueza pessoal dos escolares, como iremos atentar adiante, e garantia assim a manutençáo do bedelado. $\mathrm{O}$ importante a reter nesta questão é que o regimento do bedel é omisso acerca das funçóes do bedel, limitando-se a determinaçóes relativas a remuneraçôes. No entanto, daqui, e pela preocupação em assegurar sobrevivência do bedel, é possível inferir um labor constante de acompanhamento dos trabalhos diários dos escolares, que implicava o pagamento das referidas coletas.

Poucos anos depois, desta vez os estatutos de $1431^{36}$, de D. João I (1385-1433), novamente pouco nos deixam saber sobre a natureza funcional, e muito mais sobre o sistema de remuneração e compensação do ofício. Naturalmente, é significativo o facto de bedel ser uma das testemunhas e subscritor dos estatutos, o que novamente expressa o exercício administrativo e a importância na validação da documentação universitária. No entanto, não codificam as suas funçôes e referem apenas recebimento de pagamentos em géneros nas cerimónias de obtenção de graus académicos por parte dos escolares, continuando sem ter direito a um salário fixo. Refira-se, no entanto, que existem indícios que apontam ainda antes deste ano, em 1430, o bedel como procurador e a tomar posse de património do estudo, a saber a igreja de $\mathrm{S}$. Nicolau ${ }^{37}$, e na década seguinte envolvido frequentemente em questóes sobre o mau aproveitamento

34 Moreira de SÁ [et al.] (eds.), Chartularium Universitatis Portugalensis. 1288-1537, vol. 2, p. 199 (doc. n. ${ }^{\circ}$ 452).

35 Rodrigues e Veloso (eds.), Livro Verde da Universidade de Coimbra, pp. 132-133.

36 Rodrigues (ed.), Os primeiros estatutos da Universidade de Coimbra, pp. 15-25.

37 No instrumento de posse da igreja de S. Nicolau, anexa à Universidade de Lisboa, Afonso Eanes aparece expressamente mencionado enquanto bedel procurador do dicto estudo (MoreIRA DE SÁ [et al.] (eds.), Chartularium Universitatis Portugalensis. 1288-1537, vol. 3, p. 401 (doc. n. ${ }^{\text {931) }}$ ). 
DE OFICIAL ADMINISTRATIVO A AGENTE FINANCEIRO: EVOLUÇÃO DO CARGO DE BEDEL NO STUDIUM GENERALE PORTUGUÊS (1309-1537)

ANA PEREIRA FERREIRA E RUI M. ROCHA

de rendas anexas à Universidade ${ }^{38}$. Embora estas ocorrências sejam pontuais, são potencialmente significativas, no âmbito do exercício do ofício, pois permitem antever um desenvolvimento no sentido à congregação de funçôes na manutenção da esfera material do Estudo.

Decorrente das funçôes de redação e validação da documentação do Estudo Geral, o exercício esporádico de funçóes de procurador parece fazer todo o sentido, sobretudo se atentarmos que dentro do oficialato universitário, o bedel teria, nas palavras de Maria Helena da Cruz Coelho, «um real conhecimento dos problemas institucionais, levando, por certo, a uma maior eficácia no agir $\aleph^{39}$. Desta forma, o detentor do cargo de bedel, seria naturalmente o indivíduo melhor equipado para representar a Universidade em disputas patrimoniais.

Em 1447, o bedel ganha novas funçóes, quando por ordem do infante D. Henrique, então protetor do Estudo (protetorado 1418-1460) ${ }^{40}$, fica responsável pelo registo das faltas dos lentes para que estas fossem respetivamente descontadas no salário. Diz o documento em cada sabado vaa o bedel per todallas scollas (...) e saiba per juramento quamtas liçōes erraram aquella somana e assente-as em seu livro e de-as em rool ao recebedor pera lho descomtar ${ }^{41}$. Embora esta função seja administrativa, tem implicaçóes financeiras severas, pois permite à Universidade um aproveitamento dos seus recursos mais eficaz, a partir de deduçôes salariais.

$\mathrm{Na}$ sequência desta determinação, no ano de 1467, o sucessor de D. Henrique na proteçáo do Estudo, o infante D. Fernando (protetorado 1460-1470) ${ }^{42}$ exige, para o pagamento dos salários dos oficiais e dos lentes, um alvará lavrado pelo bedel a certificar a sua atividade no ano transato. Desta forma, todas as despesas relacionadas com salários estavam diretamente dependentes da autorização e certificaçáo do bedel. Diz o documento que daqui emdiante nom seja paguo offçial algum (...) nem leente ssem aver alvara do dito bedel de çertidam como aquele anno servio Continuadamente no qual alvara o dito bedel ponha as fautas que cada hun fizer e aponte pera lhe seer tirado do solário ${ }^{43}$. A autoridade do bedelado crescia e a condiçấo económica e financeira da Universidade dependiam cada vez mais da competência deste oficial.

Chegamos assim aos estatutos de $1503^{44}$, de D. Manuel I (1495-1521), o conjunto documental que mais nos deixam a saber sobre as funçôes do bedelado português. Pela primeira vez, era reservado para o bedel um salário fixo, na ordem dos 3000 reais anuais, além de receber quantias varáveis pela prestação de serviços e pelas cerimónias de graduação. Verifica-se assim algum poder económico, e seguramente um dos oficiais com fontes de rendimento mais diversificadas na esfera universitária portuguesa (sem que nos seja possível, para

38 A título de exemplo veja-se MoreIra De Sá [et al.] (eds.), Chartularium Universitatis Portugalensis. 1288-1537, vol. 4, pp. 307-308 (doc. n. ${ }^{\circ} 1233$ ).

39 Coelho, «As Finanças», pp. 63-64.

40 Fernandes (coord.), História da Universidade Medieval em Lisboa. Séculos XIII-XVI, p. 407.

41 Rodrigues e Veloso (eds.), Livro Verde da Universidade de Coimbra, p. 198.

42 Fernandes (coord.), História da Universidade Medieval em Lisboa. Séculos XIII-XVI, p. 407.

43 Moreira de SÁ [et al.] (eds.), Chartularium Universitatis Portugalensis. 1288-1537, vol. 6, p. 423 (doc. $\mathrm{n}^{\circ}$ 2192).

44 Rodrigues (ed.), Os primeiros estatutos da Universidade de Coimbra, pp. 29-41. 
DE OFICIAL ADMINISTRATIVO A AGENTE FINANCEIRO: EVOLUÇÃO DO CARGO DE BEDEL

já, aferir em que é que isso se concretiza). Mas voltemos a isto mais tarde, focando agora as suas funçóes. Os estatutos manuelinos confiam ao bedel um número de tarefas crescente, e que implicam um envolvimento profundo em diversos aspetos da administração do Estudo Geral. Estaria assim responsável pela redação de todos os documentos ordenados pelo reitor, conselheiro e deputados; pelos traslados dos privilégios; pela redação das cartas de grau; pelos juramentos dos escolares para obtenção de grau; pela recolha e vigilância das armas dos escolares; pelo controlo do vestuário dos escolares, mestres e doutores; pela realização de audiências e punição do conservador do Estudo na falta delas; pela comunicação por escrito das cátedras vacantes; pelo controlo de faltas dos lentes; pelas matrículas dos escolares em cada ano; pela leitura anual e pública dos estatutos universitários; mas também, pelo arrendamento das rendas; pelas quitaçôes e pelo registo das receitas e despesas da Universidade. Denota-se sobretudo uma crescente codificação das funções do bedel, e um envolvimento em quase todos os aspetos da vida académica na idade média.

Embora a maioria das tarefas do bedel sejam de âmbito burocrático e administrativo, nota-se sobretudo um gradual aumento de responsabilidades que incidiam na esfera material da Universidade, pela qual o bedel tinha o dever, não somente, de zelar, mas também de controlar. No final do século XIV, o bedelado assume por inerência, e por determinação régia, o cargo de escrivão das rendas da Universidade. Ao longo do século $\mathrm{XV}$, os pagamentos de salários, tanto dos lentes como dos oficiais, ficam progressivamente sujeitos ao aval e autorização do bedel. Nesse mesmo período, aparece frequentemente associado a contendas patrimoniais, nas quais assumia naturalmente a função de defesa dos interesses do Estudo. E finalmente, no começo do século Xvı, no âmbito da reforma universitária de D. Manuel ${ }^{45}$, o bedel é, como acabamos de referir, responsável pelo registo das receitas e despesas, bem como pelo aproveitamento e rentabilização dos bens do Estudo Geral Português.

\subsection{Mecanismos de remuneração do oficio}

Ao longo do texto anterior fomos fazendo referência aos pagamentos ao bedel pelos seus serviços prestados à Universidade. De facto, a remuneração do oficialato, deveria representar um encargo importante no balanço financeiro do Estudo Geral Português, especialmente se tivermos em conta os parcos recursos que detinham, e a dificuldade, em muitos casos, em cobrar as rendas que lhes tinham sido atribuídas pelo poder régio ${ }^{46}$.

45 Para este assunto, existe atualmente a investigação em curso de Rui M. Rocha para a sua tese de doutoramento intitulada A Reforma Manuelina da Universidade: cultura letrada e sociedade politica no Renascimento.

46 Veja-se, por exemplo, as sucessivas dificuldades em torno das rendas das igrejas anexas de Pombal e Soure, que motivadas pela transferência da Universidade para Lisboa em 1338, eximem-se do pagamento a que estavam obrigados (MoreIra de SÁ [et al.] (eds.), Chartularium Universitatis Portugalensis. 1288-1537, vol. 1, pp. 148-149 (doc. n. $\left.{ }^{\circ} 132\right)$ ); Santa Maria de Óbidos, cujo o prior solicita a redução da contribuição acordada devido aos efeitos da peste negra (MoreIra DE SÁ [et al.] (eds.), Chartularium Universitatis Portugalensis. 12881537, vol. 1, pp. 307-307 (doc. n. ${ }^{\circ}$ 288)); e Sacavém, que invocava igualmente a incapacidade de suprir os pagamentos devidos à universidade (MoreIra dE SÁ [et al.] (eds.), Chartularium Universitatis Portugalensis.

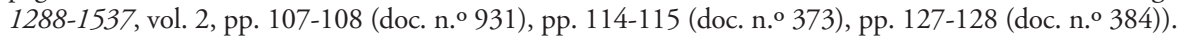


DE OFICIAL ADMINISTRATIVO A AGENTE FINANCEIRO: EVOLUÇÃO DO CARGO DE BEDEL NO STUDIUM GENERALE PORTUGUÊS (1309-1537)

ANA PEREIRA FERREIRA E RUI M. ROCHA

Focando o caso do bedelado, ao que tudo indica, o pagamento deste ofício esteve durante a maior parte da idade média dependente exclusivamente do pagamento de coletas.

A primeira referência aos proventos do ofício surge apenas em 1415, no chamado Regimento do bedel ${ }^{47}$. Como referimos anteriormente, este documento corresponde à decisão emanada pelos reitores, que tendo reunido em conselho extraordinário a propósito da contenda que opunha os escolares ao então bedel João de Braga, acerca dos montantes a pagar pelos primeiros ao segundo, determinaram os valores das coletas a cobrar anualmente pelo bedel aos escolares. Neste caso, o pagamento atenderia a critérios de riqueza pessoal dos visados. Os beneficiados da igreja catedral e outros beneficiados honrados pagariam 20 reais e 3,5 libras. Outros beneficiados pagariam 15 reais. Os escolares que não fossem detentores de benefícios pagariam 10 reais, exceto os nobres que pagariam segundo a sua pessoa. Os escolares pobres de S. Nicolau teriam direito ao menor pagamento, na ordem dos 5 reais anuais. Novamente, importante a reter nesta questão é que a manutenção do bedelado, no início do século XV parecia depender exclusivamente, ao que sabemos, da cobrança de coletas aos escolares, sendo que o seu detentor não auferia qualquer salário ou renda fixa pelo exercício do cargo.

A situação permanece igual em $1431^{48}$, nos estatutos joaninos expedidos naquele ano. Mais uma vez, o documento não codifica as funçóes, mas prevê pagamentos em géneros, também ao bedel, nas cerimónias para obtençáo de graus académicos por parte dos escolares. Para se submeter a provas de exame o bacharelando teria que pagar 1 coroa ao bedel; o candidato ao grau de licenciatura teria que oferecer um vestuário simples como the compete; e o candidato ao grau de doutor teria que oferecer ao bedel um vestuário forrado, de cor semelhante, e de pano e capuz apropriados. Nota-se assim que o bedel, em contraponto com os demais oficiais, e pelo exercício constante e participação diária nos atos públicos académicos, inseria-se no grupo restrito que mais fontes de rendimentos conseguia assegurar do funcionamento corrente do Estudo Geral, continuando, todavia, sem ter direito a um salário fixo. Isto não significa necessariamente que fosse o oficial, ou elemento da Universidade, que mais dividendos retirava do exercício do seu ofício, pois não é possível contabilizar o número de ocorrências e, portanto, os valores reais auferidos pelo bedelado.

Chegamos novamente aos estatutos de 1503, de D. Manuel $\mathrm{I}^{49}$, o conjunto documental que pela primeira vez, como referimos anteriormente, previa para o bedel um salário fixo na ordem dos 3000 reais anuais, além de receber pela prestação de serviços e pelas cerimónias de graduação. Pelas cartas de grau recebia 1 real, enquanto que pelos alvarás receberia 100 reais cada um. Das cerimónias de obtenção de grau caberia ao bedel 1 dobra d'Ouro de banda (do candidato a bacharel); uma loba de pano fino de 6 côvados ou 2000 reais por ela, bem como 1 galinha, 1 canada de vinho branco e 1 canada de vinho tinto (por parte dos candidatos ao grau de licenciado); e 3000 reais, em equiparação com o vestuário previsto nos estatutos anteriores ${ }^{50}$, de que estavam isentos os lentes em

47 Rodrigues e Veloso (eds.), Livro Verde da Universidade de Coimbra, pp. 132-133.

48 Rodrigues (ed.), Os primeiros estatutos da Universidade de Coimbra, pp. 19-23.

49 Rodrigues (ed.), Os primeiros estatutos da Universidade de Coimbra, pp. 29-41.

50 E ao scrivam e bedel tres mil reaees comformando-nos com ho statuto antigo que the dava veste forrada (Rodrigues (ed.), Os primeiros estatutos da Universidade de Coimbra, p. 38). 
DE OFICIAL ADMINISTRATIVO A AGENTE FINANCEIRO: EVOLUÇÃO DO CARGO DE BEDEL

exercício (do candidato ao grau doutor). Verifica-se assim, novamente, algum poder económico, e seguramente um dos oficiais com mais fontes de rendimento na esfera universitária portuguesa. No entanto, é importante ressalvar que apesar da referida diversidade nas fontes, o valor do salário fixo deveria funcionar apenas como um complemento aos rendimentos variáveis, pois era muito inferior ao dos professores, que auferiam entre 30000 e 10000 reais, e dos restantes oficiais, que começava nos 3000 e ascendia até aos 6000 reais (como é o caso da maioria do oficialato remunerado, nomeadamente do conservador, recebedor, e guarda das escolas) $)^{51}$.

Ademais, embora este tipo de recebimento seja previsivelmente pouco significativo na globalidade do orçamento do bedel, cabiam a este oficial parte das apreensóes decorrentes das infraçóes dos escolares e professores da Universidade. Note-se, no entanto, que estas prerrogativas tinham uma forte intenção normativa e punitiva, e não parece verosímil que tivessem sido delineadas com motivaçôes financeiras. É provável que a compensação para o bedelado representasse somente um incentivo para o cumprimento escrupuloso por parte do oficial das suas obrigaçóes de supervisão e confiscação de bens. Ao bedel cabia então metade das armas apreendidas, bem como metade do vestuário (pelotes, capuzes, barretes, gibóes e cintos de ouro) $\operatorname{confiscados}^{52}$, sem que seja possível contabilizar também em que é que este direito se materializava realmente.

A acrescentar a estes rendimentos, o conselho universitário atribuiu ao bedel, a 17 de fevereiro de 1509 , uma importância anual, na ordem dos 400 reais, para a compra de papel e tinta ${ }^{53}$, indispensável ao exercício das suas funçóes. Desta forma, o bedel via caucionada a sua despesa com material ligado ao seu ofício, representando uma importante fonte de rendimento.

Mas porque o poder económico não se concretiza apenas na receita, mas também na ausência de despesas e nos privilégios inerentes ao ofício, importa salientar também este outro aspeto. D. Henrique, enquanto protetor do Estudo, ao prover a Universidade de edifícios para o funcionamento das suas atividades em $1431^{54}$, determinou que na casa pequena, que estaa da máo esquerda desta casa [referindo-se à casa onde estaria alojada a sala de atos] more o bedel, e huum Casejro, que tenha as ditas casas limpas, e as abra e çarre, quando comprir ${ }^{5}$. Garantia desta forma a facilidade de acompanhamento dos trabalhos do Estudo Geral, essenciais para o sucesso da instituição, mas simultaneamente atribuía ao bedel um importante privilégio, que significava na realidade, e em termos financeiros, a ausência de um encargo pesado para este oficial. Não sendo possível descriminar em concreto os valores envolvidos, é sem dúvida uma importante conquista para o detentor

51 Rodrigues (ed.), Os primeiros estatutos da Universidade de Coimbra, p. 30.

52 Rodrigues (ed.), Os primeiros estatutos da Universidade de Coimbra, p. 34.

53 Moreira de SÁ, Artur [et al.] (eds.). Auctarium Chartularii Universitatis Portugalensis. 1506-1537. Lisboa: Instituto de Alta Cultura-Instituto Nacional de Investigação Científica, 1973-1979, vol. 1, p. 89 (doc. n. ${ }^{\circ} \mathrm{CXXX)}$.

54 Para mais informaçóes veja-se Loвo, Rui. «As quatro sedes do Estudo Geral de Lisboa (12901537)». In Fernandes (coord.), História da Universidade Medieval em Lisboa. Séculos XIII-XVI, pp. 279-280.

55 Moreira de SÁ [et al.] (eds.), Chartularium Universitatis Portugalensis. 1288-1537, vol. 4, p. 29 (doc. n. ${ }^{\circ}$ 956). 
DE OFICIAL ADMINISTRATIVO A AGENTE FINANCEIRO: EVOLUÇÃO DO CARGO DE BEDEL NO STUDIUM GENERALE PORTUGUÊS (1309-1537)

ANA PEREIRA FERREIRA E RUI M. ROCHA

do cargo, que se via assim isento de uma despesa significativa. Esta prerrogativa aliada ao recebimento de um salário fixo (que seria regulamentado apenas no começo da centúria de quinhentos) e de um conjunto muito diversificado de coletas (tanto pela redação e validação de documentos como pela participação em cerimónias de concessão de graus académicos), conferiam ao bedelado em Portugal, uma situação vantajosa perante os demais oficiais.

Em suma, o bedel via-se beneficiado, especialmente desde o segundo quartel do século Xv, com um conjunto de rendas, direitos e isençôes que lhe conferiam algum potencial e capacidade económica na esfera universitária portuguesa, estando, desse modo, assegurada estatutariamente a manutenção do detentor do cargo.

\section{Carreiras E percursos do bedelado PORTUguês}

Sabemos pelas carreiras traçadas de alguns dos bedéis que eram escolares, formados muitas das vezes em Direito ${ }^{56}$. O cargo, no reino português, era conseguido por meio de uma eleição anual pelos escolares, segundo nos diz a Magna Carta de D. Dinis ${ }^{57}$. Porém, temos também um caso em que o cargo passou de um tio para um sobrinho: Fernão Gonçalves, que foi bedel entre 1456 e 1498, teria o seu sobrinho João Afonso a suceder-lhe no cargo. Tal facto leva-nos a crer que, ainda que o cargo fosse por eleição, poderiam haver recomendaçôes de determinados indivíduos para ocupar o oficio que ficasse vago.

Frequentemente temos indício de longas carreiras (ver fig. 2), ainda que existam alguns casos que não passem de um ano de ofício. Estes podem facilmente explicar-se não por ser-lhes negada reeleiçáo anual, mas provavelmente pelas parcas fontes de que dispomos para poder conhecer melhor este cargo. Assim, não temos declaradamente homens que tenham desempenhado o cargo apenas um ano, temos sim pouca ou nenhuma informação sobre os anos anteriores e posteriores àquele em que temos conhecimento que estiveram no ofício.

Temos, ainda assim, uma média de 10 anos de carreira distribuídos por 12 bedéis entre 1309 e 1537. O que tem maior longevidade de carreira é Fernão Gonçalves, com 42 anos no cargo, seguido do seu sobrinho João Afonso com 33 anos de ofício e Afonso Eanes, com 27 anos. Temos 4 casos que apenas sabemos que tenham tido o oficio durante o ano, mas existem espaços incompletos nessas alturas, pelo que é possível que tenham desempenhado funções por mais tempo. Estes 4 casos de um ano são João Domingos (1326), Afonso Esteves (1358), João Gonçalves (1388) e João de Braga, que apenas sabemos que foi bedel anteriormente a 1414 .

No caso de Portugal, todos os bedéis que conhecemos tinham formação na Universidade, ainda que não saibamos se adquiriram os graus no Estudo português ou noutros reinos. Dada a especificidade e alcance das funçôes do bedel, é normal que fosse exigido,

56 Fernandes, Hermenegildo. «Instrumentos». In Fernandes (coord.), História da Universidade Medieval em Lisboa. Séculos XIII-XVI, pp. 429 e 520-521.

57 Rodrigues e Veloso (eds.), Livro Verde da Universidade de Coimbra, pp. 23-28. 


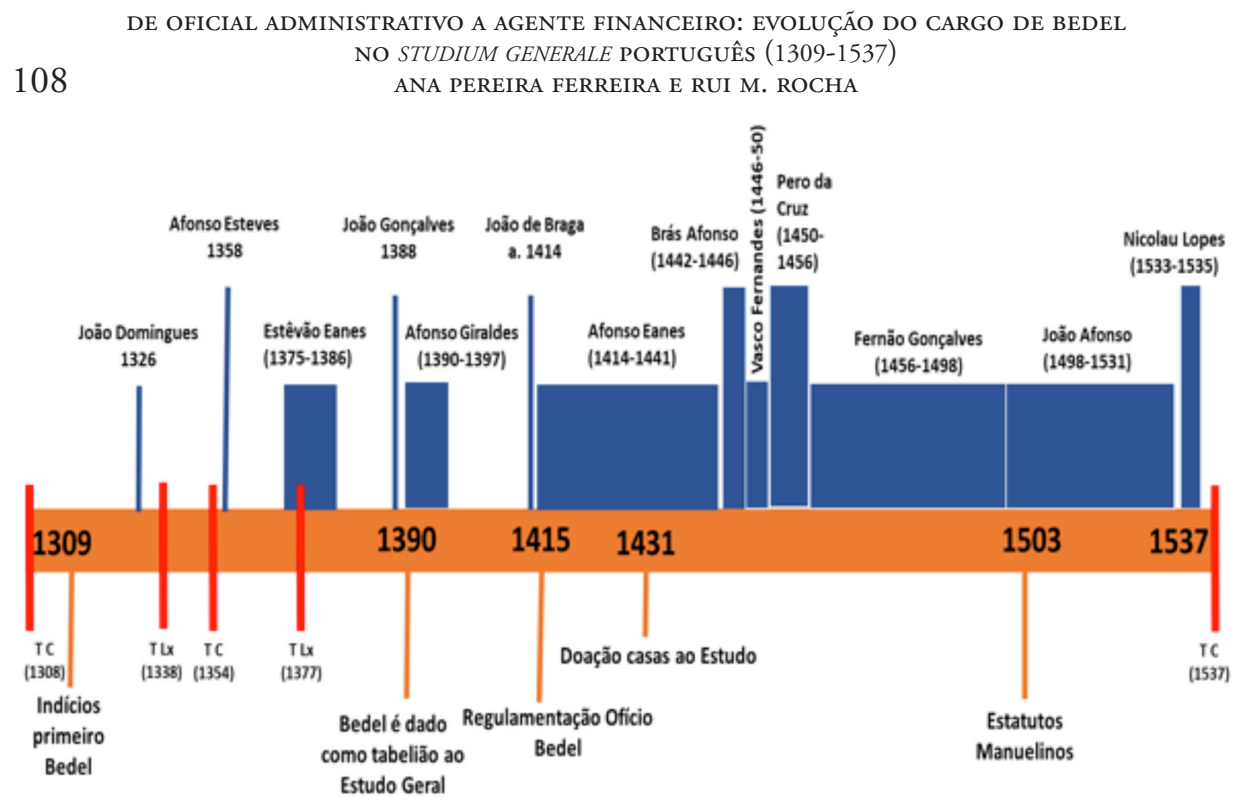

FIG. 2. Cronologia e carreiras do bedelado.

no mínimo, um grau em Artes, e podiam inclusivamente frequentar, ou ter frequentado, estudos mais avançados em Direito. Isto é, aliás, um pouco o que se passa por toda a Europa, e em particular, depois da transição entre o século XV e $\mathrm{XVI}^{58}$.

O primeiro bedel que temos conhecimento com uma carreira superior a um ano é Estêvão Eanes. Foi num documento inédito, fruto da investigação no projecto Oeconomia Studii, que ficámos a saber que Estêvão Eanes já era bedel em 1375, uma vez que é citado como testemunha num emprazamento e é denominado como Estêvão Eanes bedel do Estudo Geral ${ }^{59}$. Este documento trouxe uma informação que até aqui não tínhamos como provar para o oficio de bedel, ainda que o soubéssemos que assim sucedia para outros cargos inerentes ao estudo, como o de Reitor: independentemente das mudanças frequentes entre Lisboa e Coimbra, o caso de Estêvão Eanes demonstra que, à partida, os indivíduos manteriam o cargo na transição de um local para o outro. Ainda que a nomeação de procurador não seja algo permanente, mas de cariz momentâneo, conforme a necessidade, facto é que Estêvão Eanes chegou a representar a Universidade em assuntos externos.

Outro caso de carreira com alguma longevidade é o de Afonso Geraldes ${ }^{60}$, que foi escolar de Leis (1433 e 1434) e bedel do Estudo Geral de Lisboa (onde produz 10 treslados enquanto tabelião da Universidade). Sabemos ainda que foi nomeado por D. João I como escrivão das rendas do Estudo Geral de Lisboa (1390) e sendo tabelião do Estudo

58 Ruegg, Walter e Ridder-Symoens, Hilde de (eds.). Uma História da Universidade na Europa II. As Universidades na Europa Moderna (1500-1800). Lisboa: INCM-Imprensa Nacional Casa da Moeda, 2001, p. 165.

59 ANTT, Mosteiro de Sta. Cruz de Coimbra, livro 40, fl. $24 \mathrm{v}-25$.

60 Fernandes, «Instrumentos», pp. 399 e 429. 
DE OFICIAL ADMINISTRATIVO A AGENTE FINANCEIRO: EVOLUÇÃO DO CARGO DE BEDEL NO STUDIUM GENERALE PORTUGUÊS (1309-1537)

ANA PEREIRA FERREIRA E RUI M. ROCHA

Geral, tornou-se no primeiro a acumular as funçôes. No que respeita às suas redes clientelares, temos ainda a informaçáo de que era vassalo d'el-rei e membro do Desembargo Régio, onde subscreve cinco cartas régias datadas de 1433, 1434, 1439. Ora, Afonso Geraldes foi membro do Desembargo anos depois de ter sido bedel do Estudo, o que nos pode levar a pressupor que em alguns casos o bedel fosse um cargo que acumulassem com os estudos ou uma forma de depois de ganharem experiência e prestígio profissional e social, ascenderem.

Outro caso sobre o qual temos alguns dados é o de Afonso Eanes ${ }^{61}$. A data da sua morte será no ano de 1441. Temos a informação de que foi escolar em Cânones (1414) e escolar em Leis (1430). Sabemos também que foi criado do rei D. Joáo I e procurador do infante D. Henrique, tendo por isso uma relação privilegiada com o poder, à semelhança do anteriormente referido Afonso Geraldes. Sabemos que foi casado com Graça Lourenço ( $†$ antes de 1451), a qual tinha umas casas em Lisboa e percebemos que adquiriu, pelo casamento, um casal em Queijas. Foi bedel e notário do Estudo Geral de Lisboa (desde, pelo menos, 1414 e até à sua morte). A informação é dada pelo Regimento do Bedel onde consta o seu nome, em 1415 e como sendo sucessor do bedel Joăo de Braga. Durante o seu bedelado, foi aprovado o Regimento do Bedel do Estudo Geral (1415) e os Estatutos do Estudo Geral de Lisboa (1431). Além de bedel, era ainda procurador do Estudo Geral e do Mosteiro de Odivelas, mostrando por isso ser um homem influente.

Brás Afonso ${ }^{62}$ foi bedel por apenas 4 anos, mas sabemos que foi escolar em Direito Canónico (1440-1441). Há ainda informação de que terá sido lente de Cânones no Estudo Geral de Lisboa (1442) e procurador de Fernando Álvares, prior de Santo Estêvão de Alfama. Foi eleito bedel e escrivão público do Estudo Geral de Lisboa e foi confirmado no cargo pelo rei em 1442, renunciando ao cargo em 1446. Em 1443, fez-se substituir por Diogo Gonçalves enquanto bedel. Foi vigário-geral do deão e cabido de Lisboa (1440-1441); nessa qualidade, atuou como juiz da cúria arquiepiscopal, passando duas cartas de sentença. Foi nomeado ouvidor na Corte (1446) e escrivão perante o corregedor da Corte, em substituiçāo de Lopo Rodrigues, que renunciara ao ofício (1456).

Fernão Gonçalves ${ }^{63}$ foi escolar em Leis (1456) e como já referido, tio de João Afonso, eleito seu sucessor no bedelado do Estudo Geral de Lisboa. Foi bedel e público notário do Estudo Geral de Lisboa (1456 até 1498, data em que renunciou ao cargo, dizendo que havia mais de 40 anos que servia no oficio de bedelado com ha maior deligemcea que elle sempre podee $E$ que ao presente asy por ser mujto velho E com [o] por gramde jmfirmidade sua nom pudia seruyr ho dicto oficio asy Como era hobrigado, pedindo que fosse nomeado em seu lugar o seu sobrinho João Afonso, o qual tinha já ofício de escrever por especial mandado d'el-rei, e recebendo parte do seu mantimento. Exerceu ainda funçôes de procurador do Estudo Geral, tendo apresentado ao bispo de Lamego, D. Rodrigo de Noronha, a bula de Sisto IV relativa à anexação de uma conezia de cada sé catedral do reino à Universidade de Lisboa, e ao corregedor da cidade de Lisboa, licenciado Lopo da Fonseca, o instrumento de posse de uma conezia e prebenda da Sé de Lisboa em favor da Universidade.

61 FERNANDES, «Instrumentos», pp. 520-521.

62 FERnANDES, «Instrumentos», pp. 457-458.

63 Fernandes, «Instrumentos», pp. 497-498. 
João Afonso ${ }^{64}$, era sobrinho de Fernão Gonçalves. Foi bedel e público notário, por autoridade régia, do Estudo Geral de Lisboa, cargo para que foi eleito em 1498, por sugestão de seu tio Fernáo Gonçalves (sendo que ficou com parte do seu mantimento), tendo sido confirmado no cargo por D. Manuel I, na qualidade de protetor do Estudo Geral, em 1499. Redigiu vários diplomas relativos ao Estudo Geral até, pelo menos, 1531.

Por fim, na nossa cronologia temos Nicolau Lopes, que apenas desempenhou o cargo por dois anos. Também ele era Bacharel.

\section{Consideraçốes Finais}

Naturalmente, estas circunstâncias, e a nossa perspetiva sobre elas, estão pontualmente condicionadas pela crescente e evolutiva codificação normativa das responsabilidades do oficialato, que nem sempre acompanhou a sua natureza prática. Quer isto dizer que, apesar de em cronologias mais recuadas, e referimo-nos ao início dos séculos XIV e $\mathrm{XV}$, as informaçóes serem residuais, não implica necessariamente que algumas das características encontradas no início do século XVI não se verificassem já anteriormente. Por esta razão, muitas das conclusóes são meramente e necessariamente especulativas. Não obstante e em contraponto - e é importante salientar este aspecto - houve transformaçôes (e acumulaçôes de funçôes) inegáveis, assinaladas no tempo pelo esforço legislativo de as vincular.

$\mathrm{Da}$ informação que dispomos, verificamos que na generalidade, as atribuiçóes do bedel, no início do século xIV estão muito em linha com as que existem nas restantes Universidades europeias. De reter, ainda assim, que o caso português tem algumas particularidades, seja pela itinerância das instalaçóes do Estudo e o acompanhamento dos oficiais nesta itinerância, seja pelo cariz de tabelião que é dado ao bedel, podendo assim lavrar documentos com auctoritas e fides publica. Contudo, de frisar que muito raramente o bedel se autodenomina tabelião do estudo, preferindo designar-se na documentação como bedel do Estudo e escrivão público ou referindo-se ao documento que lavra como sendo fruto de autoridade régia. Talvez porque achasse que seria inferior considerar-se tabelião, uma vez que notamos que todos os bedéis tinham frequência universitária, normalmente em Direito.

Parece-nos que o bedelado absorvia grande parte do tempo destes homens, não nos parecendo possível a acumulação de funçôes num período mais tardio. Talvez tal pudesse suceder numa fase inicial, em que a responsabilidade e atribuição de funçôes não era ainda tấo exigente. Ainda assim, e apesar de termos longas carreiras e casos que o cargo é deixado por velhice ou morte (como Fernão Gonçalves e Afonso Eanes, respectivamente), verificamos que noutros casos o bedelado era uma etapa de uma carreira, que poderia ir desde o ensino (temos os casos de Brás Afonso e Vasco Fernandes, ambos com apenas 4 anos no cargo, talvez justificado precisamente pelo facto de serem lentes em Cânones ${ }^{65}$ ), ao funcionalismo público, nomeadamente o caso de Afonso Geraldes, que viria a fazer

64 FERNANDES, «Instrumentos», pp. 501-502.

65 Fernandes, «Instrumentos», pp. 430-431 e 457-458. 
DE OFICIAL ADMINISTRATIVO A AGENTE FINANCEIRO: EVOLUÇÃO DO CARGO DE BEDEL NO STUDIUM GENERALE PORTUGUÊS (1309-1537)

ANA PEREIRA FERREIRA E RUI M. ROCHA

parte do Desembargo régio na década de 30 do século $\mathrm{Xv}^{66}$. De igual relevo, o facto de alguns bedéis terem importantes redes clientelares e de vassalagem, como os exemplos de Afonso Geraldes que era vassalo do próprio monarca e de Afonso Eanes, que era criado do rei e procurador do Infante D. Henrique.

Embora as funçóes do bedelado português sejam sempre eminentemente administrativas a ligadas à burocracia da instituição, o cargo assume-se lentamente como um agente de relativa importância na esfera material e financeira do Estudo Geral. Dele estavam dependentes os pagamentos de salários e outras despesas correntes, o controlo e registo da receita e despesa, o arrendamento de bens e pontualmente a responsabilidade de representar o Estudo nas disputas patrimoniais. Era por isso um elemento crucial no funcionamento regular e quotidiano da Universidade, estando profundamente envolvido nas questôes de aproveitamento e manutenção do património universitário, ou por outras palavras, o bedel era o oficial administrativo por excelência, mas também um importante agente financeiro cuja competência era fundamental para o sucesso do Estudo Geral português.

\section{REFERÊNCIAS BIBLIOGRÁFICAS}

Arquivo Nacional/Torre do Tombo (ANTT), Mosteiro de Sta. Cruz de Coimbra, livro 40.

Coelho, Maria Helena da Cruz. "Coimbra et l'université: complémentarités et oppositions». In Gilli, Patrick; Verger, Jacques e Le BlÉvec, Daniel. Les universités et la ville au Moyen Âge. Cohabitacion et tension. Turnhout: Brill, 2007, pp. 309-326.

Coelmo, Maria Helena da Cruz. «As Finanças». In História da Universidade em Portugal. Lisboa: Fundação Calouste Gulbenkian, 1997, vol. I, tomo I, pp. 39-67.

Coelho, Maria Helena da Cruz; Fernandes, Hermenegildo e Vilar, Hermínia. «O Studium medieval português: singularidades de um caso periférico». Studia Historica. Historia Medieval, 2018, vol. 36, n. ${ }^{\circ}$ 2, pp. 83-115.

Fernandes, Hermenegildo (coord.). História da Universidade Medieval em Lisboa. Séculos XIII-XVI. Lisboa: Tinta da China, 2013.

Fernandes, Hermenegildo. «Instrumentos». In Fernandes, Hermenegildo (coord.). História da Universidade Medieval em Lisboa. Séculos XIII-XVI. Lisboa: Tinta da China, 2013, pp. 429 e 520-521.

Ferreira, Ana Pereira e Rocha, Rui Miguel. "A cidade e a Universidade: indícios de exclusão social dos escolares nos alvores do Estudo Geral Português». In Solórzano Telechea, Jesús Ángel (coord.). Exclusión y orden social en la ciudad medieval europea. Logroño: Instituto de Estudios Riojanos, 2018, pp. 91-120.

García y García, Antonio. "Consolidaciones del siglo xV». In Rodríguez-San Pedro Bezares, Luis E. (coord.). Historia de la Universidad de Salamanca. I, Trayectoria y vinculaciones. Salamanca: Ediciones Universidad de Salamanca, 2002, pp. 39-64.

García y García, Antonio. "Génesis de la Universidad, siglos XiII-XIV». In Rodríguez-San PeDro Bezares, Luis E. (coord.). Historia de la Universidad de Salamanca. I, Trayectoria y vinculaciones. Salamanca: Ediciones Universidad de Salamanca, 2002, pp. 21-38.

História da Universidade em Portugal. 2 vols. Coimbra-Lisboa: Universidade de Coimbra-Fundação Calouste Gulbenkian, 1997.

66 Fernandes, «Instrumentos», p. 429. 
DE OFICIAL ADMINISTRATIVO A AGENTE FINANCEIRO: EVOLUÇÃO DO CARGO DE BEDEL NO STUDIUM GENERALE PORTUGUÊS (1309-1537)

ANA PEREIRA FERREIRA E RUI M. ROCHA

Lobo, Rui. «As quatro sedes do Estudo Geral de Lisboa (1290-1537)». In Fernandes, Hermenegildo (coord.). História da Universidade Medieval em Lisboa. Séculos XIII-XVI. Lisboa: Tinta da China, 2013, pp. 267-304.

Martins, Armando. "Lisboa, a cidade e o Estudo: a Universidade de Lisboa no primeiro século da sua existência». In Fernandes, Hermenegildo (coord.). Universidade Medieval em Lisboa séculos XIII-XVI. Lisboa: Tinta da China, 2013, pp. 41-88.

MoreIra de SÁ, Artur [et al.] (eds.). Auctarium Chartularii Universitatis Portugalensis. 1506-1537. 3 vols. Lisboa: Instituto de Alta Cultura-Instituto Nacional de Investigação Científica, 1973-1979.

MoreIra de SÁ, Artur [et al.] (eds.). Chartularium Universitatis Portugalensis (1288-1537). 16 vols. Lisboa: Instituto de Alta Cultura-Instituto Nacional de Investigação Científica-Junta Nacional de Investigação Científica e Tecnológica-Fundação para a Ciência e a Tecnologia, 1966-2004.

Moreira de SÁ, Artur. O Infante D. Henrique e a Universidade. Lisboa: Comissão Executiva das Comemoraçôes do Quinto Centenário da Morte do Infante D. Henrique, 1960.

Rodrigues, Manuel Augusto (ed.). Os primeiros estatutos da Universidade de Coimbra. Coimbra: Arquivo da Universidade de Coimbra, 1991.

Rodrigues, Manuel Augusto e Veloso, Maria Teresa Nobre (eds.). Livro Verde da Universidade de Coimbra. Coimbra: Arquivo da Universidade, 1992.

Ruegg, Walter e Ridder-Symoens, Hilde de. Uma História da Universidade na Europa I. As Universidades na Idade Média. Lisboa: INCM-Imprensa Nacional Casa da Moeda, 1996.

Ruegg, Walter e Ridder-Symoens, Hilde de (eds.). Uma História da Universidade na Europa II. As Universidades na Europa Moderna (1500-1800). Lisboa: INCM-Imprensa Nacional Casa da Moeda, 2001.

Sánchez Movellán, Elena. «La época medieval». In Palomares IbáNez, Jesús María (coord.). Historia de la universidad de Valladolid, I. Valladolid: Universidad de Valladolid, 1989, pp. 27-71.

VergER, Jacques. «Déspenses universitaires à Avignon au $\mathrm{Xv}^{\mathrm{e}}$ siècle (1455-1456)». In Institut de Recherches et d'Etudes du Bas Moyen Âge Avignonnais [et al.]. Avignon au Moyen Âge. Textes et documents. Avignon: Aubanel, 1988, pp. 207-218.

Universidade(s). História. Memória. Perspectivas. Actas do Congresso «História da Universidade» (no 7. ${ }^{\circ}$ Centenário da sua fundação). 5 a 9 de Março de 1990, 5 vols., Coimbra: Comissão Organizadora do Congresso «História da Universidade», 1991. 